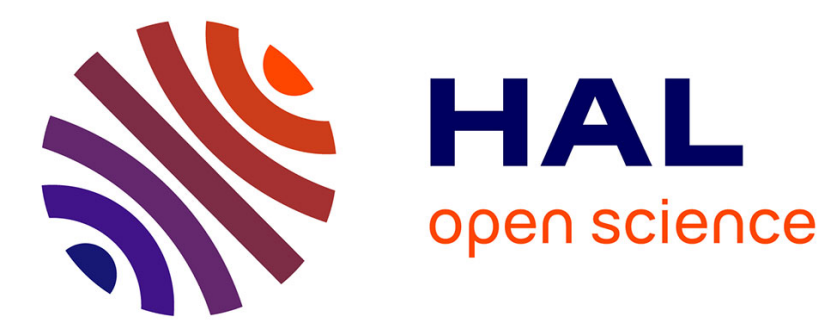

\title{
Tunable white light in trivalent europium single doped tin fluorophosphates ultra-low melting glass
}

Wei Mao, Muzhi Cai, Wenqing Xie, Panpan Li, Wenyan Zhen, Shiqing Xu, Junjie Zhang

\section{- To cite this version:}

Wei Mao, Muzhi Cai, Wenqing Xie, Panpan Li, Wenyan Zhen, et al.. Tunable white light in trivalent europium single doped tin fluorophosphates ultra-low melting glass. Journal of Alloys and Compounds, 2019, 805, pp.205-210. 10.1016/j.jallcom.2019.07.014 . hal-02281765

HAL Id: hal-02281765

https://hal-univ-rennes1.archives-ouvertes.fr/hal-02281765

Submitted on 17 Oct 2019

HAL is a multi-disciplinary open access archive for the deposit and dissemination of scientific research documents, whether they are published or not. The documents may come from teaching and research institutions in France or abroad, or from public or private research centers.
L'archive ouverte pluridisciplinaire HAL, est destinée au dépôt et à la diffusion de documents scientifiques de niveau recherche, publiés ou non, émanant des établissements d'enseignement et de recherche français ou étrangers, des laboratoires publics ou privés. 


\section{Tunable white light in trivalent europium single doped tin fluorophosphates ultra-low melting glass}

Wei Mao ${ }^{1}$, Muzhi Cai ${ }^{1,2}$, Wenqing Xie ${ }^{1}$, Panpan $\mathrm{Li}^{1}$, Wenyan Zhen ${ }^{1}$, Shiqing Xu ${ }^{1}$, Junjie Zhang ${ }^{1{ }^{*}}$

${ }^{1}$ College of Materials Science and Engineering, China Jiliang University, Hangzhou 310018, China

${ }^{2}$ Univ Rennes, CNRS, ISCR (Institut des Sciences Chimiques de Rennes) UMR 6226, F-35000 Rennes, France.

*Corresponding author: jjzhang@cjlu.edu.cn

\section{ABSTRACT}

In recent years, low melting temperature glasses have received wide attention as the hosts of phosphor-converted light emitting diodes (pc-WLED). In this work, a series of trivalent europium doped tin fluorophosphates glasses were prepared by conventional melting method. Under ultraviolet excitation, the blue-green broadband emission from $\mathrm{Sn}^{2+}$ activation centers in the glass matrix and the red emission of $\mathrm{Eu}^{3+}$ ions together constituted a cool white luminescence. The spectra analysis was used to demonstrate the energy transfer between $\mathrm{Sn}^{2+}$ centers and $\mathrm{Eu}^{3+}$ ions. The results showed that $\mathrm{Sn}^{2+}$ and $\mathrm{Eu}^{3+}$ possessed independent intrinsic emission and mutual energy transfer simultaneously. The ${ }^{5} \mathrm{D}_{4}$ and ${ }^{5} \mathrm{G}_{2}$ excited states of $\mathrm{Eu}^{3+}$ ion favored the energy transfer to $\mathrm{Sn}^{2+}$ center, the ${ }^{5} \mathrm{~L}_{6}$ excited state of $\mathrm{Eu}^{3+}$ ion would absorb more of the energy by the $\mathrm{Sn}^{2+}$ ground state excitation to contribute on red emission. Therefore, the fluorescent glass can transform cool white light to warm white light by changing the excitation wavelength. The tunable white light is obtained in the WLED devices built with the glass and commercial UV chips.

\section{Keywords}

tin fluorophosphates glass; ultra-low melting glass; warn white light; light emitting diodes

\section{Introduction}

In general, many of the low and ultra-low melting temperature glasses, including tin 
fluorophosphates glass, barium fluoride-thorium fluoride glass, phosphate glass, boron lead glass and so on [1-5], have been widely used in glass-metal sealing, IC packaging, Phosphor-in-Glass (PiG) host [6-9]. Specially, the tin fluorophosphates $\left(\mathrm{SnF}_{2}-\mathrm{P}_{2} \mathrm{O}_{5}-\mathrm{SnO}\right)$ glass, of which the glass transition temperature $(\mathrm{Tg})$ value is generally lower than $200{ }^{\circ} \mathrm{C}$, has been considered to be an excellent host of fluorescent glass in the past two decades. Unlike the conventional encapsulant material, i.e., organic silicone or resin, tin fluorophosphates glass avoids the problem of the serious yellowing and aging issues, which leads to luminous efficacy degradation and color shifting in WLED [10]. On the other hand, the tin fluorophosphates glass, doping the rare earth metals, also has been showed to be a promising host to achieve photon conversion in solar cell applications [11]. However, the luminescent materials consisting of $\mathrm{SnF}_{2}-\mathrm{P}_{2} \mathrm{O}_{5}-\mathrm{SnO}$ glass host containing trivalent rare earth (RE) ions have rarely been researched, which is suspected of potential application value in white fluorescent lamp, the pc-WLED and laser.

In recent years, the tunable white fluorescent materials basing on the tin-containing inorganic glass matrix have received wide attention. It is considered to be an excellent matrix for the preparation of white fluorescence glass, of which the $\mathrm{Sn}^{2+}$ activation center can emit a broadband blue-green emission with short lifetime and high quantum efficiency. Therefore, a high quality white light can be obtained by simply doping suitable activator. Hirokazu Masai et al. firstly reported that $\mathrm{SnO}-\mathrm{ZnO}-\mathrm{P}_{2} \mathrm{O}_{5}$ low-melting glasses showed a broadband blue luminescence with high efficiency, which was described as the emission of $\mathrm{Sn}^{2+}$ defects as an activation center in the subsequent research [12-13]. Simultaneously, an adjustable white light emission with a high value of quantum efficiency (QE) was obtained by doping $\mathrm{Mn}^{2+}$ ions into the $\mathrm{SnO}-\mathrm{ZnO}-\mathrm{P}_{2} \mathrm{O}_{5}$ glass matrix [14]. In the tin fluorophosphates glass matrix $\left(\mathrm{SnF}_{2}-\mathrm{P}_{2} \mathrm{O}_{5}-\mathrm{SnO}\right)$, Wang et al. reported a similar broadband visible luminescence, which was also recognized as the contribution of the $\mathrm{Sn}^{2+}$ centers. Utilizing the efficient energy transfer from $\mathrm{Sn}^{2+}$ to 
$\mathrm{Mn}^{2+}$, a warm white fluorescence was obtained. It is worth noting that tin-containing glass materials have been focused on the study of transition metals (TM) doping luminescent materials, however, the optical properties of rare earth doped tin-containing inorganic glass have been rarely studied.

Compared with TM ions, the 4f-4f state of RE ions exhibits stable and complex transition energy levels, which makes the energy transfer process of the multi-activator system exhibit special luminescence characteristics [15]. The $\mathrm{Eu}^{3+}$ ion, as a kind of typical trivalent $\mathrm{RE}$ ions, has been frequently applied in phosphor crystals, quantum dots and luminescent glasses [16-17]. On one hand, the energy transitions from the excited ${ }^{5} \mathrm{D}_{0}$ level to the ${ }^{7} \mathrm{~F}_{\mathrm{J}}(\mathrm{J}=0,1,2,3,4,5,6)$ emission levels of $\mathrm{Eu}^{3+}$ provide a stable red emission to material hosts. On the other hand, as one kind of well-known probe ions, the characteristic peak located at $620 \mathrm{~nm}$ of $\mathrm{Eu}^{3+}$ ions will be affected by the change in the surrounding crystal field environment [18]. In many researches, Eu doped white fluorescent has been obtained by energy conversion between multi-activators, such as $\mathrm{Eu}^{2+} / \mathrm{Eu}^{3+}[19], \mathrm{Cu}^{2+} / \mathrm{Eu}^{3+}[20], \mathrm{Ag} / \mathrm{Eu}^{3+}$ [21], $\mathrm{Sb}^{3+} / \mathrm{Eu}^{3+}[22]$ in proper materials.

In this text, using the $60 \mathrm{SnF}_{2}-30 \mathrm{P}_{2} \mathrm{O}_{5}-10 \mathrm{SnO}$ glass matrix as an example, we prepared a series of $\mathrm{Eu}^{3+}$-doped tin fluorophosphates glasses by conventional melting method. The energy conversion relationship between the $\mathrm{Sn}^{2+}$ activation center and $\mathrm{Eu}^{3+}$ ions was investigated by spectrum spectral analysis. And by adjusting the excitation wavelength, the tunable emission from cold white to warm white was obtained in the $\mathrm{Eu}^{3+}$ doped $\mathrm{SnF}_{2}-\mathrm{P}_{2} \mathrm{O}_{5}-\mathrm{SnO}$ glasses. Finally, a WLED device model based on this fluorescent glass was produced with commercial ultraviolet (UV) chips.

\section{Experimental}

Glass samples were prepared using reagent-grade $\mathrm{SnF}_{2}$ (99.99\%, metals basis), $\mathrm{NH}_{4} \mathrm{H}_{2} \mathrm{PO}_{4}(99.99 \%$, metals basis), $\mathrm{SnO}(99.9 \%$, metals basis $)$ and $\mathrm{Eu}_{2} \mathrm{O}_{3}((99.99 \%$, metals basis $))$ as starting materials. These 
starting materials were carefully mixed and melted in alumina crucibles heated to $350{ }^{\circ} \mathrm{C}$ for 20 minutes. After melting, the glass melts were poured into a cold stainless-steel mold for quenching in air and cooled to room temperature directly. The mixing and heating steps were similar for all glasses, and the melting temperature and time for homogenization were the same. All samples were cut and polished into $10 \times 10 \times 2 \mathrm{~mm}^{3}$ for further measurement.

Absorption spectra were obtained by using a Perkin Elmer Lambda 900UV-VIS-NIR spectrophotometer in the range of 190-800 $\mathrm{nm}$ with a resolution of $1 \mathrm{~nm}$. The photoluminescent (PL) and photoluminescent excitation PLE spectra were collected by a high resolution spectrofluorometer (Fluorolog 3-211, Horiba Jobin Yvon Inc., Edison, NJ) using a $450 \mathrm{~W}$ Xe-lamp as the excitation source. The pump light beams were incident and the emitted light beams were collected both at a $45^{\circ}$ degree angle to the plate normal with the same slit width for all samples, while reported data were corrected for instrumental response. The color rendering index and absolute quantum efficiency of glasses were measured in a integrating sphere with a high sensitive spectrometer (Nova, Idea Optics Instruments).All the measurements were carried out at room temperature.

\section{Results and Discussion}

Regarding the thermal properties of $\mathrm{SnF}_{2}-\mathrm{P}_{2} \mathrm{O}_{5}-\mathrm{SnO}_{5}$ glass, it has been enthusiastically studied in recent years $[11,23]$. More than $40 \mathrm{~mol} \%$ of the $\mathrm{P}_{2} \mathrm{O}_{5}$ content leads to the awful chemical stability of the glass and is sensitive to water. However, if the content of $\mathrm{P}_{2} \mathrm{O}_{5}$ is less than $25 \mathrm{~mol} \%$, it will be disadvantageous for the formation of the glass network. Therefore, in our work, $30 \mathrm{~mol} \%$ content of $\mathrm{P}_{2} \mathrm{O}_{5}$ was chosen and kept invariable for the following experiment. As the proportion of stannous fluoride $\left(\mathrm{SnF}_{2}\right)$ increases, the melting temperature of the glass gradually decreases. When $60 \mathrm{~mol} \%$ is reached, the glass transition temperature is as low as $98^{\circ} \mathrm{C}[23]$. For our desire to explore the optical 
properties of rare earth doped ultra-low melting glass, the $60 \mathrm{SnF}_{2}-30 \mathrm{P}_{2} \mathrm{O}_{5}-10 \mathrm{SnO}_{5}$ (TFP) glass is chose as trivalent Eu doped glass matrix. Herein, $\mathrm{x} / 2 \mathrm{Eu}_{2} \mathrm{O}_{3}-60 \mathrm{SnF}_{2}-30 \mathrm{P}_{2} \mathrm{O}_{5}-10 \mathrm{SnO}_{5}$ glasses were collectively referred to as TFPxEu.
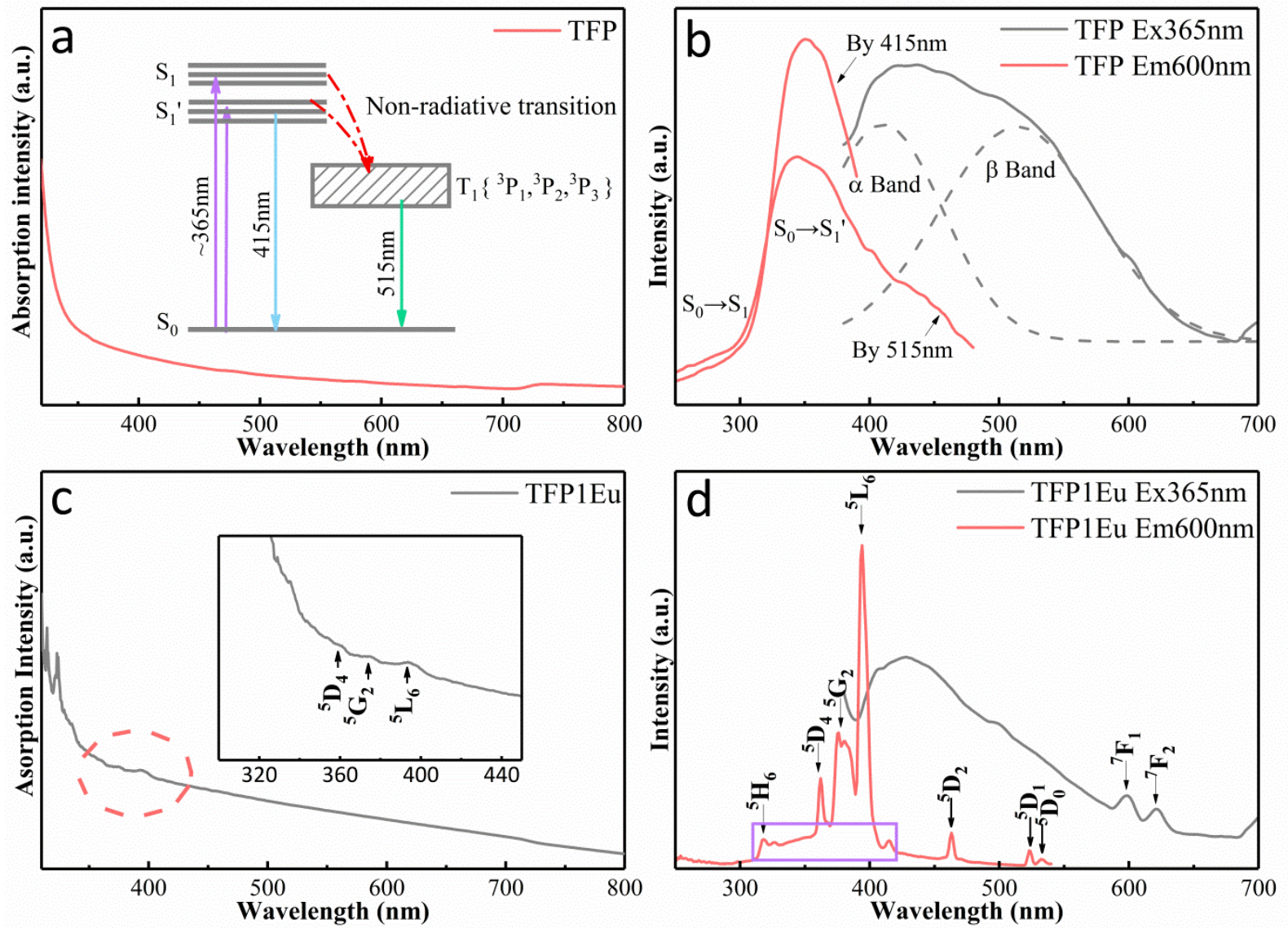

Fig. 1. (a) The absorption spectrum of the TFP. The inset is a schematic representation of the energy levels of the $\mathrm{Sn}^{2+}$ activation center. (b) The PL and PLE spectra of the TFP. (c) The absorption spectra of the TFP1Eu. (d) The PL and PLE spectra of the TFP1Eu and TFP matrix.

The absorption spectrum of the TFP sample is shown in the Fig. 1(a). The undoped tin fluorophosphates glass exhibits a significant red shift of ultraviolet absorption edge compared with conventional phosphate glasses, which originates from the $\mathrm{Sn}^{2+}$ activation center. The triplet $\left(\mathrm{T}_{1}\right)$-singlet $\left(\mathrm{S}_{0}\right)$ relaxation band model has been commonly used to describe the emission mechanism of $\mathrm{Sn}^{2+}$ center. The PL and PLE spectra are reflected in Fig. 1(b), which can more accurately reflect the energy level of 
the $\mathrm{Sn}^{2+}$ activation center. Under the $365 \mathrm{~nm}$ excitation, the TFP matrix shows a broadband blue emission from $390 \mathrm{~nm}$ to $600 \mathrm{~nm}$. The broadband emission at $428 \mathrm{~nm}$ corresponds to the emissions of $\mathrm{S}_{1}$ and $\mathrm{T}_{1}$ states of the $\mathrm{Sn}^{2+}$ activation center, which are defined as $\alpha$-band [singlet $\left(\mathrm{S}_{1}\right)$-singlet $\left(\mathrm{S}_{0}\right)$ ] and $\beta$-band [triplet $\left(\mathrm{T}_{1}\right)$-singlet $\left.\left(\mathrm{S}_{0}\right)\right][13,24]$. The PLE spectra of the $415 \mathrm{~nm}$ and $515 \mathrm{~nm}$ emissions suggest the wide excited state. It is worth mentioning that the excited state of $\mathrm{Sn}^{2+}$ can be divided into $\mathrm{S}_{1}$ state (high energy band) and $S_{1}^{\prime}$ state (low energy band). The $S_{1}^{\prime}$ state is confirmed to be a strongly concentration dependent excitation band, and its relaxation process from $S_{1}{ }^{\prime}$ to $T_{1}$ state has been considered to be the key to high quantum efficiency of tin-containing glass. In the inset of Fig. 1(a), the energy transfer of $\mathrm{Sn}^{2+}$ activation center is described. The $\mathrm{Sn}^{2+}$ activator in tin fluorophosphates glass is transferred to the excited state by the ground state absorption: $S_{0}+h v(\sim 3.39 \mathrm{eV}) \rightarrow S_{1}$. By nonradiation transition, a part of the absorbed photons in $S_{1}$ state relaxed to ground state: $S_{1} \rightarrow S_{0}$ ( $\alpha$-band emission), from which produces the blue emission of $3.02 \mathrm{eV}(415 \mathrm{~nm})$. And another part of energy for ground state absorption: $\mathrm{T}_{1} \rightarrow \mathrm{S}_{0}+\mathrm{hv}(2.41 \mathrm{eV}, \beta$-band emission).

The absorption, PL and PLE spectra of the TFP1Eu sample are showed in the Fig. 1 (c) and (d) respectively. When doping the $\mathrm{Eu}^{3+}$ ions, it exhibits a strong absorption band in the region of 300 to 400 $\mathrm{nm}$ compared with the absorption of TFP matrix. And the main peaks at $360 \mathrm{~nm}, 375 \mathrm{~nm}$ and $395 \mathrm{~nm}$ correspond to the ground excitation of $\mathrm{Eu}^{3+}$ ion: ${ }^{7} \mathrm{~F}_{0} \rightarrow{ }^{5} \mathrm{D}_{4},{ }^{5} \mathrm{G}_{2}$ and ${ }^{5} \mathrm{~L}_{6}$ respectively. Under the $365 \mathrm{~nm}$ excitation, the TFP1Eu sample shows a similar broadband emission as the TFP sample in the blue-green region. What is different is that the TFP1Eu sample exhibits two sharp peaks at $600 \mathrm{~nm}$ and $620 \mathrm{~nm}$, which correspond to the radiation transitions of the ${ }^{5} \mathrm{D}_{0}$ states to ${ }^{7} \mathrm{~F}_{1},{ }^{7} \mathrm{~F}_{2}$ states of the $\mathrm{Eu}^{3+}$ ions, respectively. The excitation range of TFP1Eu at $600 \mathrm{~nm}$ covers the range of excitation and emission of TFP glass, which appears as narrow linewidth emissions corresponding to the absorption level of Eu ${ }^{3+}$ 
ions. Among them, the energy transfers of ${ }^{7} \mathrm{~F}_{0} \rightarrow{ }^{5} \mathrm{~L}_{6}$ and ${ }^{5} \mathrm{D}_{2}$ are in the emission band of $\mathrm{Sn}^{2+}$. It indicates the presence of energy transfer between the $\mathrm{Sn}^{2+}$ excitation center and the $\mathrm{Eu}^{3+}$ ions in the prepared $\mathrm{Eu}^{3+}$ doped TFP glass. At the same time, a clear wide excitation band can be seen in the range marked by the purple frame, which overlaps with the excitation band of $\mathrm{Sn}^{2+}$ in the TFP glass. It is worth mentioning that the ${ }^{5} \mathrm{~L}_{6}$ excited state of $\mathrm{Eu}^{3+}$ ion shows strongest excitation intensity in the PLE spectrum of TFP1Eu compared to weak intensity of the ${ }^{5} \mathrm{D}_{4}$ and ${ }^{5} \mathrm{G}_{2}$ excited states, which suggests that the energy levels of the $\mathrm{Eu}^{3+}$ ion possess different trends to energy transfer. 

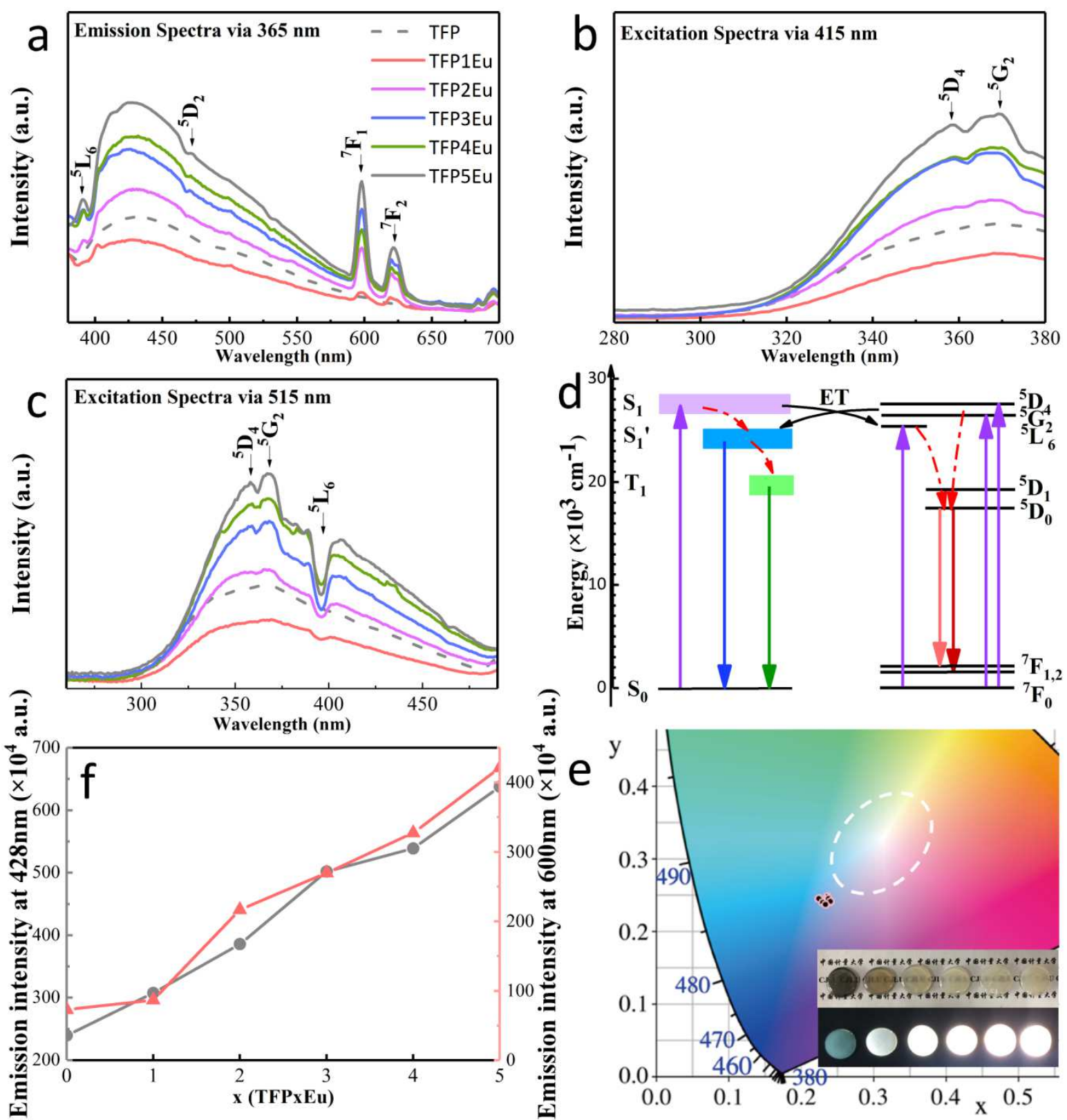

Fig. 2. (a) The PL spectra of the TFPxEu samples excited by $365 \mathrm{~nm}$. And the PLE spectra of the TFPxEu samples at $415 \mathrm{~nm}$ (b) and $515 \mathrm{~nm}$ (c). (d) The energy -level diagram of the $\mathrm{Sn}^{2+}$ and $\mathrm{Eu}^{3+}$ and the description of energy transfer (ET). (e) the dependence of the emission intensity of the TFPxEu sample at $428 \mathrm{~nm}$ (blue line) and $600 \mathrm{~nm}$ (red line) on the Eu ${ }^{3+}$ ions doping concentration under the excitation at $365 \mathrm{~nm}$. (f) The two-dimensional color coordinates of TFPxEu samples. The digital photograph of the samples is in the inset.

In order to more deeply understand the energy transform mechanism of $\mathrm{Sn}^{2+}$ centers and $\mathrm{Eu}^{3+}$ ions in $\mathrm{Eu}^{3+}$ doped $\mathrm{SnF}_{2}-\mathrm{P}_{2} \mathrm{O}_{5}-\mathrm{SnO}$ glass, a series of TFPxEu ( $\mathrm{x}=1,2,3,4$ and 5) glasses are prepared with the same melting process. The Fig. 2 (a) is the PL spectra of TFPxEu samples. As the concentration of Eu ${ }^{3+}$ 
increasing, the emission intensity is gradually enhanced, including the broadband emission at $\sim 428 \mathrm{~nm}$ belonging to the $\mathrm{Sn}^{2+}$ center and the sharp peaks at $600 \mathrm{~nm}$ and $620 \mathrm{~nm}$ of the ${ }^{7} \mathrm{~F}_{\mathrm{J}}(\mathrm{J}=1,2)$ states. At the same time, the characteristic peaks of the ${ }^{5} \mathrm{~L}_{6}$ and ${ }^{5} \mathrm{D}_{2}$ emitted states belonging to Eu ${ }^{3+}$ appear at $395 \mathrm{~nm}$ and $464 \mathrm{~nm}$ in the broadband emission clearly. Further, the emission intensity at $\sim 395 \mathrm{~nm}$ is significantly reduced. The energy transfer of $\mathrm{Sn}^{2+}$ to $\mathrm{Eu}^{3+}$ was demonstrated in previous discussion, which can explain the decrease of emission intensity at $\sim 428 \mathrm{~nm}$ in TFP1Eu. The increase of emission intensity at $\sim 428 \mathrm{~nm}$ is attributed to the energy transfer of $\mathrm{Eu}^{3+}$ ions to $\mathrm{Sn}^{2+}$ centers.

The PLE spectra of the TFPxEu samples emitted at $415 \mathrm{~nm}$ and $515 \mathrm{~nm}$ are shown in Fig. 2 (b) and (c) respectively. Their change in excitation intensity is consistent with the change in emission intensity of Fig. 2 (a). As the increasing doping concentration of $\mathrm{Eu}^{3+}$ ions, the characteristic excited states of ${ }^{5} \mathrm{~L}_{6}$ and ${ }^{5} \mathrm{D}_{2}$ belonging to $\mathrm{Eu}^{3+}$ gradually become apparent, which proves the energy feedback of Eu ${ }^{3+}$ ions to the $\mathrm{Sn}^{2+}$ centers. Further, it is worth noting that there is deep pit at $\sim 395 \mathrm{~nm}$ in the PL excitation spectra at $415 \mathrm{~nm}$ and $515 \mathrm{~nm}$. In combine with the excitation spectrum of the TFP1Eu in Fig. 1 (d), it suggests that the ${ }^{5} \mathrm{~L}_{6}$ excited state of $\mathrm{Eu}^{3+}$ ions receive the energy transfer from the $\mathrm{Sn}^{2+}$ activation center. The energy transfer model of $\mathrm{Sn}^{2+}$ and $\mathrm{Eu}^{3+}$ is depicted in Fig. 2(d). Under the excitation at $\sim 365 \mathrm{~nm}$, the luminescence of the $\mathrm{Sn}^{2+}$ centers and the $\mathrm{Eu}^{3+}$ ions presence independent stimulated emission processes. Furthermore, these two activators exhibit a mutual energy transfer process. The $\mathrm{S}_{1}$ state of the $\mathrm{Sn}^{2+}$ activation center overlaps with the ${ }^{5} \mathrm{D}_{4}$ and ${ }^{5} \mathrm{G}_{2}$ excited states of $\mathrm{Eu}^{3+}$ ion, and the $\mathrm{S}_{1}$, state is similar to the ${ }^{5} \mathrm{~L}_{6}$ emission state of $\mathrm{Eu}^{3+}$ ion, they perform mutual energy transfer.

The mechanism for the blue-green emission can be expressed as: Intrinsic emission of $\mathrm{Sn}^{2+}$ : $\mathrm{S}_{1} / \mathrm{S}_{1}{ }^{\prime}\left(\mathrm{Sn}^{2+}\right)+\mathrm{T}_{1}\left(\mathrm{Sn}^{2+}\right) \rightarrow \mathrm{S}_{0}\left(\mathrm{Sn}^{2+}\right)$; Energy transfer of $\mathrm{Eu}^{3+}$ ion to $\mathrm{Sn}^{2+}:{ }^{7} \mathrm{~F}_{0}\left(\mathrm{Eu}^{3+}\right) \rightarrow{ }^{5} \mathrm{D}_{4}\left(\mathrm{Eu}^{3+}\right)+$ ${ }^{5} \mathrm{G}_{2}\left(\mathrm{Eu}^{3+}\right) \rightarrow \mathrm{S}_{1}{ }^{\prime}\left(\mathrm{Sn}^{2+}\right)$. 
The mechanism for the red emission can be expressed as: Intrinsic emission of $\mathrm{Eu}^{3+}:{ }^{7} \mathrm{~F}_{0}\left(\mathrm{Eu}^{3+}\right) \rightarrow$ ${ }^{5} \mathrm{D}_{4}\left(\mathrm{Eu}^{3+}\right)+{ }^{5} \mathrm{G}_{2}\left(\mathrm{Eu}^{3+}\right)+{ }^{5} \mathrm{~L}_{6}\left(\mathrm{Eu}^{3+}\right.$, mainly $) \rightarrow{ }^{5} \mathrm{D}_{0}\left(\mathrm{Eu}^{3+}\right) \rightarrow{ }^{7} \mathrm{~F}_{\mathrm{J}}(\mathrm{J}=1,2)\left(\mathrm{Eu}^{3+}\right)$; Energy transfer of $\mathrm{Sn}^{2+}$ to $\mathrm{Eu}^{3+}: \mathrm{S}_{1}\left(\mathrm{Sn}^{2+}\right) \rightarrow{ }^{5} \mathrm{~L}_{6}\left(\mathrm{Eu}^{3+}\right) \rightarrow{ }^{5} \mathrm{D}_{0}\left(\mathrm{Eu}^{3+}\right) \rightarrow{ }^{7} \mathrm{~F}_{\mathrm{J}}(\mathrm{J}=1,2)\left(\mathrm{Eu}^{3+}\right)$

Fig. 2 (e) shows the dependence of the emission intensity of the TFPxEu sample at $428 \mathrm{~nm}$ and 600 $\mathrm{nm}$ on the $\mathrm{Eu}^{3+}$ ions doping concentration under the excitation at $365 \mathrm{~nm}$. Due to the energy feedback process of $\mathrm{Eu}^{3+}$ ions to $\mathrm{Sn}^{2+}$ centers, the broadband emission belonging to $\mathrm{Sn}^{2+}$ increases with the concentration of $\mathrm{Eu}^{3+}$, which is disadvantageous for the desired white light emission. In the Fig. 2 (f), the emission spectra data of the TFPxEu sample are reflected in the two-dimensional color coordinates. All the samples shown in the Fig. 2 (f) emerge similar cool white light, which are consistent with the digital photograph of the sample at $365 \mathrm{~nm}$ excitation in the inset. 

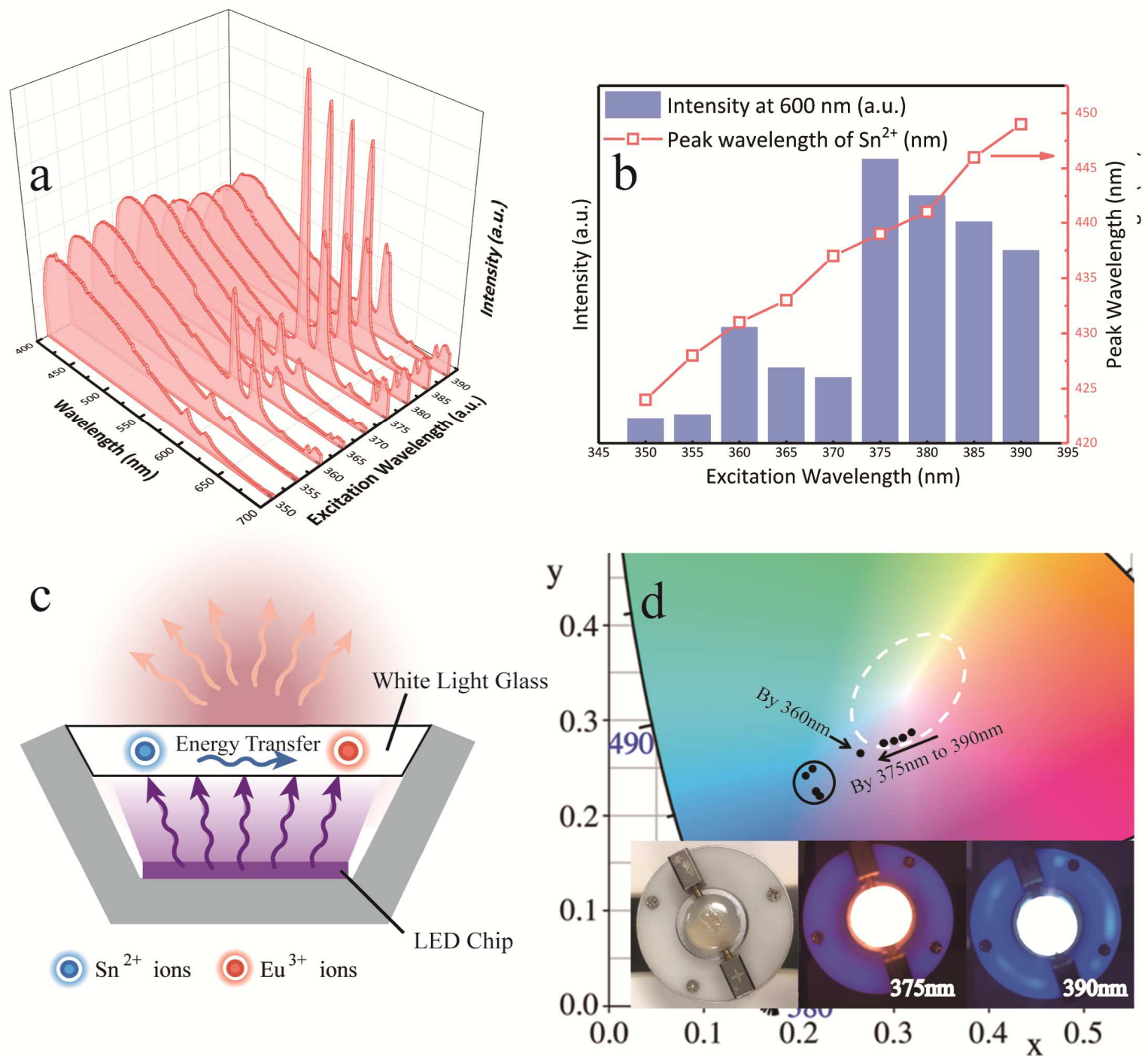

Fig. 3 (a) The PL spectra of the TFP5Eu samples with the different excitation wavelength form $350 \mathrm{~nm}$ to $390 \mathrm{~nm}$. (b) The dependence between the excitation wavelength with emission peak position of $\mathrm{Sn}^{2+}$ (Red) and the emission intensity at $600 \mathrm{~nm}$ (Black), respectively. (d) The two-dimensional color coordinates of TFP5Eu samples. The digital photograph of the TFP5Eu under the different excitation is in the inset.

Due to the TFP5Eu sample has the strongest emission intensity, this sample is used as the research object. The Fig. 3 (a) is the PL spectra of TFP5Eu sample under the different excitation wavelength from $350 \mathrm{~nm}$ to $390 \mathrm{~nm}$. As the excitation wavelength increases, the emission peaks in the blue-green band are continuously red-shifted, which corresponds to the change of the $S_{1}$ to $S_{0}$ transitions in the $\mathrm{Sn}^{2+}$ center. At the same time, the emission of $600 \mathrm{~nm}$ and $620 \mathrm{~nm}$ belonging to $\mathrm{Eu}^{3+}$ ions is also affected. The 
dependence of both these on the excitation wavelength is depicted in Fig. 3 (b). In Fig. 3(b), the emission peak of the $\mathrm{Sn}^{2+}$ centers exhibits an approximately linear change with respect to the excitation wavelength, which is advantageous for the production of white light with high color rendering index. On the other hand, the emission law of ${ }^{5} \mathrm{D}_{0} \rightarrow{ }^{7} \mathrm{~F}_{\mathrm{J}}$ in $\mathrm{Eu}^{3+}$ ions is consistent with the results discussed previously. By regulating the excitation wavelength, the red portion of emission of TFP5Eu sample is enhanced and a warm white light is obtained using the energy transfer difference of the ${ }^{5} \mathrm{~L}_{6}$ excited state and the ${ }^{5} \mathrm{D}_{4},{ }^{5} \mathrm{G}_{2}$ excited states. The results are clearly shown in the color coordinates of Fig. 3 (d). Among them, when the excitation wavelength is changed from $375 \mathrm{~nm}$ to $390 \mathrm{~nm}$, the sample color gradually changes from warm white light to cool white light.

Table 1. The fluorescent properties of WLED devices based TFP5Eu sample with 375nm and 390nm chips

\begin{tabular}{|c|c|c|c|c|c|}
\hline \multirow{2}{*}{ WLED device } & \multicolumn{2}{|c|}{ CIE coordinates } & Color $\mathrm{Re}$ & \multirow{2}{*}{$\begin{array}{l}\text { Absolute quantum } \\
\text { efficiency }( \pm 5 \%)\end{array}$} & \multirow{2}{*}{$\begin{array}{l}\text { Color } \\
\text { Temperature(K) }\end{array}$} \\
\hline & $\mathrm{x}$ & $\mathrm{y}$ & Index $(\mathrm{Ra})$ & & \\
\hline $375 \mathrm{~nm}$ & 0.33 & 0.30 & 91.8 & 6.12 & 5896 \\
\hline $390 \mathrm{~nm}$ & 0.30 & 0.29 & 88.3 & 6.70 & 8815 \\
\hline
\end{tabular}

Further, in order to demonstrate the previous discussion, the encapsulated WLED devices based on this glass with $375 \mathrm{~nm}$ and $390 \mathrm{~nm}$ ultraviolet chips (40mA, 5V) are also prepared, whose models shown in the Fig. 3 (c). And the digital photograph of TFP5Eu glass excited by the $375 \mathrm{~nm}$ and $390 \mathrm{~nm}$ LED chips is shown in the inset of Fig. 3 (d). The fluorescent properties of WLED devices based TFP5Eu sample with $375 \mathrm{~nm}$ and $390 \mathrm{~nm}$ chips are shown in the Table 1. Compared to conventional phosphors, the WLED devices display excellent white light consequent: the CIE values close to (0.33, 
$0.33)$, higher color rendering indexs $(\mathrm{Ra}=91.8 ; 88.3)$. It demonstrates the different willingness of different excitation states of $\mathrm{Eu}^{3+}$ ions for energy transfer. Unfortunately, the WLED devices exhibit poor QE values, which affect practical applications. In generally, the concentration of $\mathrm{Sn}^{2+}$ ions and the relaxation process from $\mathrm{S}_{1}$ state to $\mathrm{T}_{1}$ state in $\mathrm{Sn}^{2+}$ ions have been considered to be important factors affecting quantum efficiency [25-27]. Therefore, excessive concentration of $\mathrm{Sn}^{2+}$ ions and F/O proportion in tin fluorophosphoate glass are suspected to be responsible for poor quantum efficiency in our glass. It is expected that the QE value can be simultaneously improved by changing the composition ratio of $\mathrm{xSnF}_{2}-\mathrm{yP}_{2} \mathrm{O}_{5}-\mathrm{ZSnO}$, which will be the goal of further work. Moreover, compared to these glasses in the existing reports shown higher Tgs exceeding $500{ }^{\circ} \mathrm{C}$ and the melting temperatures exceeding $700{ }^{\circ} \mathrm{C}$, the tin fluorophosphoate glass we reported is still considered to be a promising candidate for WLED encapsulant materials.

\section{Conclusion}

Briefly, a series of $\mathrm{Eu}^{3+}$ doped tin fluorophosphates glasses were successfully fabricated by a conventional melt quenching process, which all emitted similar cool white fluorescence under the same ultraviolet excitation. By spectra analysis, the energy transfer processes between the $\mathrm{Sn}^{2+}$ activation centers and $\mathrm{Eu}^{3+}$ ions were analyzed. The results prove that the $\mathrm{Sn}^{2+}$ activation center and $\mathrm{Eu}^{3+}$ ions in these glasses possess intrinsic emission and mutual energy conversion. The part of energy in $\mathrm{Eu}^{3+}$ ion will transfer to the $\mathrm{Sn}^{2+}$ and participate in the emission process of $\mathrm{Sn}^{2+}$, due to the ${ }^{5} \mathrm{D}_{4}$ and ${ }^{5} \mathrm{G}_{2}$ excited states of $\mathrm{Eu}^{3+}$ ion are energetically close to the $\mathrm{S}_{1}$ state in $\mathrm{Sn}^{2+}$ center. The ${ }^{5} \mathrm{~L}_{6}$ excited state in the $\mathrm{Eu}^{3+}$ ions favor energy transfer from $\mathrm{Sn}^{2+}$ center and mainly participate in the intrinsic emission: ${ }^{5} \mathrm{~L}_{6} \rightarrow{ }^{7} \mathrm{~F}_{\mathrm{J}}$. Therefore, the luminescent color of the $\mathrm{Eu}^{3+}$ doped TFP glass can be adjusted from blue/cold white to warm white/red by controlling the excitation wavelength from $350 \mathrm{~nm}$ to $390 \mathrm{~nm}$. The encapsulated 
WLED devices based on this glass with $375 \mathrm{~nm}$ and $390 \mathrm{~nm}$ ultraviolet chips were prepared. Although the WLED device exhibits a poor QE value, it is considered desirable to increase the QE value by adjusting the chemical composition of the glass. In the word, the TFPxEu white fluorescent glass, which possesses the characteristics of mutative fluorescent colors by simply adjusting the excitation wavelength, has a promising application prospect in the field of white LEDs.

\section{Acknowledgments}

This research was financially supported by Zhejiang Provincial Natural Science Foundation of China (No LD18F050001).

\section{References}

[1] D Ehrt, Phosphate and fluoride phosphate optical glasses-properties, structure and applications. Physics and Chemistry of Glasses-European, Phys. Chem. Glasses-B. 56 (2015) 217-234.https://doi.org/10.13036/17533562.56.6.217. [2] N M Bobkova, E E Trusova, Low-melting bismuth-borate glass: composition development. Glass. Ceram. 68 (2012) 349-352.https://doi.org/ 10.1007/s10717-012-9387-3.

[3] R K Brow, C A Click, T M Alam, Modifier coordination and phosphate glass networks. J. Non-crys. Solids. 274(2000) 9-16.https://doi.org/10.1016/S0022-3093(00)00178-2.

[4] Y Cheng, $\mathrm{H}$ Xiao, W Guo, Structure and crystallization kinetics of $\mathrm{PbO}-\mathrm{B}_{2} \mathrm{O}_{3}$ glasses. Ceram. Int. 33(2007) 1341-1347. https://doi.org/10.1016/j.ceramint.2006.04.025

[5] J Varghese, T Siponkoski, M Teirikangas, Structural dielectric and thermal properties of $\mathrm{Pb}$ free molybdate based ultralow temperature glass. ACS. Sustain. Chem. Eng. 4(2016) 3897-3904.https://doi.org/10.1021/acssuschemeng.6b00721.

[6] M Cai, W Mao, L Calvez, Broadband blue emission from $\mathrm{ZnO}$ amorphous nanodomains in zinc phosphate oxynitride glass. Opt. Lett. 43(2018) 5845-5848.

[7] J J Shyu, C H Yeh, Formation and properties of SnO-MgO- $\mathrm{P}_{2} \mathrm{O}_{5}$ glasses. J. Mater. Sci. 42(2007) 4772-4777.

[8] X Xiang, B Wang, $\mathrm{H}$ Lin, Towards long-lifetime high-performance warm w-LEDs: Fabricating chromaticity-tunable glass ceramic using an ultra-low melting Sn-PFO glass. J. Eur. Ceram. Soc. 38 (2018) 1990-1997.https://doi.org/10.1016/j.jeurceramsoc.2017.10.013

[9] H Lin, T Hu, Y Cheng, Glass ceramic phosphors: towards long-lifetime high-power white light-emitting-diode 
applications-a review. Laser. Photon. Rev. 12 (2018) 1700344.

[10] L Yang, M Chen, Z Lv, Preparation of a YAG: Ce phosphor glass by screen-printing technology and its application in LED packaging. Opt. Lett. 38 (2013) 2240-2243. https://doi.org/10.1364/OL.38.002240.

[11] J York-Winegar, T Harper, C Brennan, Structure of $\mathrm{SnF}_{2}-\mathrm{SnO}_{2} \mathrm{P}_{2} \mathrm{O}_{5}$ glasses. Phys. Procedia. 44 (2013) 159-165. https://doi.org/10.1016/j.phpro.2013.04.020.

[12] H Masai, T Fujiwara, S Matsumoto S, White light emission of Mn-doped $\mathrm{SnO}-\mathrm{ZnO}-\mathrm{P}_{2} \mathrm{O}_{5}$ glass containing no rare earth cation. Opt. Lett. 36 (2011) 2868-70.

[13] H Masai, T Tanimoto , T Fujiwara. Correlation Between Emission Property and Concentration of $\mathrm{Sn}^{2+}$ Center in the SnO-ZnO-P $\mathrm{O}_{5}$ Glass. Opt. Express. 20 (2012) 27319.

[14] Y Wang, Y Li, S Han, Continuously tunable broadband emission of $\mathrm{Mn}^{2+}$ doped low melting point Sn-F-P-O glasses for warm white light-emitting diodes. J. Am. Ceram. Soc. 101 (2018) 5564-5570.

[15] B R Judd, Optical absorption intensities of rare-earth ions. Phys Rev, 127 (1962) 750. https://doi.org/10.1103/PhysRev.127.750.

[16] M Nogami, T Enomoto, T Hayakawa, Enhanced fluorescence of $\mathrm{Eu}^{3+}$ induced by energy transfer from nanosized $\mathrm{SnO}_{2}$ crystals in glass. J. Lumin. 97 (2002) 147-152. https://doi.org/10.1016/S0022-2313(02)00217-X.

[17] A Kumar, D K Rai, S B Rai, Optical studies of $\mathrm{Eu}^{3+}$ ions doped in tellurite glass. Spectrochimica. Acta. Part. A. 58 (2002) 2115-2125. https://doi.org/10.1016/S1386-1425(01)00684-9

[18] Z Li, D Zhou, Y Yang, Effects of crystal structure transformation on cooperative up-conversion luminescence in the $\mathrm{Tb}^{3+}-\mathrm{Yb}^{3+}$ co-doped oxyfluoride glass-ceramics. J. Alloy. Compd. 731 (2018) 1044-1052. https://doi.org/10.1016/j.jallcom.2017.10.055.

[19] Z Lian, J Wang, Y Lv, The reduction of $\mathrm{Eu}^{3+}$ to $\mathrm{Eu}^{2+}$ in air and luminescence properties of $\mathrm{Eu}^{2+}$ activated ZnO-B ${ }_{2} \mathrm{O}_{3}-\mathrm{P}_{2} \mathrm{O}_{5}$ glasses. J. Alloy. Compd. 430 (2007) 257-261. https://doi.org/10.1016/j.jallcom.2006.05.002.

[20] H Guo, R F Wei, X Y Liu, Tunable White Luminescence and Energy Transfer in $\left(\mathrm{Cu}^{+}\right)_{2}, \mathrm{Eu}^{3+}$ Codoped Sodium Silicate Glasses. Opt. Lett. 37 (2012) 1670-1672.

[21] M Eichelbaum, K Rademann, Plasmonic Enhancement or Energy Transfer: On the Luminescence of Gold-, Silver-, and Lanthanide-Doped Silicate Glasses and Its Potential for Light-Emitting Devices. Adv. Funct. Mater. 19 (2009) 2045-2052.

[22] Q Yu, H D Zeng, Z Liu, J Ren, G R Chen, Novel $\mathrm{Sb}^{3+} / \mathrm{Eu}^{3+}$ Co-doped phosphate luminescent glasses with adjustable emission. J. Alloy. Compd. 590 (2014) 92.

[23] H Liu, J Ma, J Gong, The structure and properties of $\mathrm{SnF}_{2}-\mathrm{SnO}-\mathrm{P}_{2} \mathrm{O}_{5}$ glasses. J. Non-Cryst. Solids. 419 (2015) 
92-96.

[24] Y Wang, Y Yu, Y Zou, Broadband visible luminescence in tin fluorophosphate glasses with ultra-low glass transition temperature. RSC. Adv. 8 (2018) 4921-4927.

[25] H Masai, Y Takahashi, T Fujiwara. High photoluminescent property of low-melting Sn-doped phosphate glass. App. Phys. Express, 3 (2010) 082102.

[26] H Masai, T Fujiwara, S Matsumoto. High efficient white light emission of rare earth-free MnO-SnO-ZnO- $\mathrm{P}_{2} \mathrm{O}_{5}$ glass. J. Ceram. Soc. Jpn. 119 (2011) 726-730.

[27] J A Jimanez. Luminescent tin-doped phosphate glasses activated by carbon. Mater. Res. Bull. 88 (2017) 131-135. 
1. This work forces on the optical spectroscopy of trivalent europium ions in tin fluorophosphates glasses.

2. The transition of the glass luminescence from blue/cold white to warm white/red is controlled by controlling the excitation wavelength from $350 \mathrm{~nm}$ to $390 \mathrm{~nm}$.

3. The WLED devices show: the higher CRI ( 90) and tunable color temperature. 